(C2007 IEEE. Personal use of this material is permitted. However, permission to reprint/republish this material for advertising or promotional purposes or for creating new collective works for resale or redistribution to servers or lists, or to reuse any copyrighted component of this work in other works must be obtained from the IEEE. 


\title{
Development and Application of Probabilistic Criteria in Value-Based Transmission System Adequacy Assessment
}

\author{
A. A. Chowdhury ${ }^{1}$, Fellow, IEEE and Syed M. Islam, Senior Member, IEEE
}

\begin{abstract}
In the past, electric utilities were continuously adding more facilities to their systems in order to satisfy the growing customer energy requirements based on a set of deterministic criteria that guide transmission planning. The traditional planning guidelines were based on planner's experience and intuition without a formal and consistent framework for their development. In most cases, using the deterministic criteria, the systems were either over or under built.

In the deregulated market, any investment decision related to transmission reliability required to be addressed on a rational and quantitative basis within a cost-benefit framework explicitly using data on the value of changes in service reliability to customers. The ultimate determination of poor or adequate transmission reliability performance in the cost-benefit planning framework is based on customer's preferences and customer mix that are unique to each transmission system. In the current competitive energy market environment, such an approach makes perfect sense. This paper presents an approach to rank the deterministic contingencies using a relative likelihood approach to the most frequent contingency of a generator outage and assign required system steady state performance requirements against high, medium and low probability contingencies. The paper then illustrates the applications of the probability based criteria in value-based transmission system reliability enhancement planning using a practical transmission system.
\end{abstract}

Key Words: Contingency ranking, planning criteria, competitive market, value-based reliability, reliability costbenefit evaluation

\section{INTRODUCTION}

Traditionally, vertically integrated utilities have applied deterministic criteria to plan and design their transmission systems. The most commonly used criterion is $\mathrm{N}-1$ contingency conditions against which system performance is tested for voltage and overload violations for the system peak loading condition. The peak loading conditions typically occur for only 3 to 5 percent of the time in a year. This deterministic criterion therefore runs the risk of over/under investment and their essential weakness is that they do not and can not account for the probabilistic or stochastic nature of power system behavior,

${ }^{1}$ Manuscript received Septemeber 20, 2007

A.A. Chowdhury, is with the MidAmerican Energy Company, USA (email: AChowdhury@caiso.com)

S. M. Islam is with the Department of Electrical and Computer Engineering, Curtin University of Technology, Australia (email: s.islam@curtin.edu.au) of customer demands, or of component failures. Deterministic criteria are normally based on planners' experience and intuition, without a formal and consistent framework for their development.

The movement towards deregulation makes the deterministic planning criteria invalid and will therefore introduce a wide range of reliability issues that will require system reliability planning criteria and tools that can incorporate the residual risks and uncertainties associated with transmission system planning and design [1]-[3]. Probabilistic transmission system planning criteria offers a rational response to these conflicting new requirements. The paper presents a transmission system reliability performance table intended for use as guidelines for planners in system planning activities and is based on the probability of occurrence of different contingencies reflecting a large measure of probabilistic content.

North American Electric Reliability Council has published bulk electric system reliability standards in which different categories of single and multiple contingencies are identified that to be tested for system adequacy and stability performance assessments. One important component that is missing in this standard is the probability of contingency occurrence and its consequences in terms of system reliability and security performance. There are contingencies with high probability of occurrences but with insignificant or no consequences, while at the same time some contingencies are least likely to occur but with high consequences of widespread load losses. Planning and designing of a power system without explicitly considering probability and consequences of contingency occurrence would inevitably render either over or under built power systems. The approach of ranking contingencies based on historical average probability of contingency occurrence in bulk system planning criteria has been considered by some utilities [4].

The majority of the utilities regularly collects information on generation and transmission equipment outages and maintains an electronic database on equipment outage statistics. In this paper, generic data on generation and transmission equipment outages are utilized to compute average contingency frequency, average duration and probability figures. The probability of multiple outages is computed and a generalized discussion of the impact of these contingencies is included. The computed contingencies are ranked and a consistent framework for system reliability performance table is developed based on these groupings. The ranked contingency based planning 
criteria is further extended in this paper in evaluating system weak areas needing reinforcements and identified system reinforcements projects are subjected to value-based tests to ascertain whether the reinforcement projects are cost justified in terms of customer reliability benefits rendered by the identified projects much outweigh the costs of those projects.

In proposing this approach as the basis for the system reliability performance measures, the basic objectives were to incorporate the benefits of explicitly accounting for the probability of system disturbances with the clarity of existing deterministic criteria. It is expected to produce a robust guide that would result in project being proposed whose costs would be justified by the value they provide to customers.

\section{CONTINGENCY RANKING}

\section{A. $\quad$ Generating Unit Outage Statistics}

Normally bulk system planning is not concerned with the determination of the adequacy of system generation capacity to meet peak loads, however inclusion of generator contingencies in transmission reliability planning criteria is important because they can lead to transmission problems. Additionally, the increased cost-effectiveness of gas fired generation has expanded the viability of judiciously locating generation to achieve transmission benefits. It is necessary to consider the performance impacts of these alternatives. Data on generator outage statistics presented in [5] is used in developing generator contingency in this paper. The basic two-state model used in computing the forced unavailability of a unit is presented Fig. 1 [6]. In this model, a unit could exist either in the up state, in other words, the units is running or in the down state which is in the state of forced out of service. $\mathbf{q}$ is the failure rate for the unit normally expressed in occurrences per year and $\mu$ is the repair rate also expressed in occurrences per year.

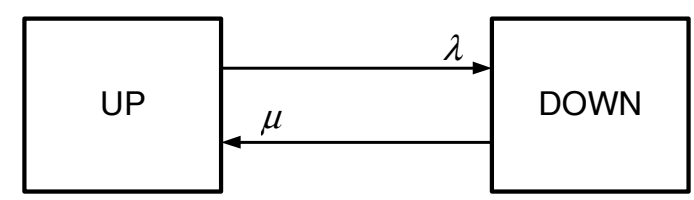

Fig. 1: A two-state model for a unit

The probability of forced outage $(\mathrm{P})$ is computed as:

$\mathrm{P}=\frac{\lambda}{\lambda+\mu}$

Multiple unit plants have been designed to minimize the likelihood that a single event will cause the loss of both units. Accordingly, outage statistics for two generating units were computed assuming event independence.

The model of Fig. 1 can also be used for transmission line and transformer unit failure modeling as discussed in Subsection B in the following.

\section{B. Transmission Equipment Outage Statistics}

For illustration purposes of the contingency ranking approach, data on transmission equipment forced outages operating at $345 \mathrm{kV}$ voltage as presented in [7], [8] have been considered in this paper. The data was resolved into line and transformer related groups to correspond to utility modeling practices for transmission planning studies.

B.1. Line Statistics

It is important to note that, in establishing contingency ranking for the transmission system, only forced sustained outages were considered. It was assumed that maintenance outages would not be performed at a time that would jeopardize the system during the next contingency.

\section{B.1.1 Multiple Outages}

Most of the multiple failures of transmission system components (transmission lines, transformers, etc.) can be grouped into the following categories:

\section{Multiple Independent Outages}

Independent outages of two or more components are referred to as overlapping or simultaneous independent outages. The outage of each component is caused by an independent event. The outage probability was computed as a product of the failure probabilities of each of the events. The mathematical models used for computing frequency, duration and unavailability involving two components overlapping independent outages are presented in Equations 2, 3 and 4.

$\mathbf{D}_{12}=\mathbf{}_{1} * \mathbf{D}_{2 *}\left(\mathrm{r}_{1}+\mathrm{r}_{2}\right) / 8760$ in occ/year

$\mathrm{r}_{12}=\mathrm{r}_{1} * \mathrm{r}_{2} /\left(\mathrm{r}_{1}+\mathrm{r}_{2}\right)$ in hours

$\mathrm{U}=\mathbf{D}_{12} * \mathrm{r}_{12} / 8760$ in per unit

Where,

$\mathbf{D}_{12}$ is the independent overlapping outage frequency of components 1 and 2

$\mathbf{D}_{1}$ is the outage frequency of component 1

$\mathbf{D}_{2}$ is the outage frequency of component 2

$\mathrm{r}_{1}$ is the average outage duration of component 1

$r_{2}$ is the average outage duration of component 2

$\mathrm{U}$ is the unavailability or probability of forced outage of both components 1 and 2 .

\section{Common Mode Outages}

A common mode outage is an event having an external cause with multiple failures where the effects are not consequences of each other. The common mode outage rate and average duration values for the $345 \mathrm{kV}$ networks were ascertained from historical field data presented in [9].

\section{Station Originated Outage}

Though infrequent, the bulk supply system does experience multiple dependent outages of transmission circuits due to stuck breaker conditions or bus section faults. Stuck breaker and bus section statistics used in contingency rankings are obtained from Reference [9].

\section{B.2. Transformer Statistics}

It is the general belief that transformer outages while infrequent, involved extended repair times. Normally 
failures involving integral subcomponents such as bushing, winding, on load tap changer or core related outages require a long repair time. However, transformer outages involving terminal equipment are of shorter duration. The transformer outage statistics for $345 \mathrm{kV}$ transformer system presented in [8] are used in this paper in contingency ranking purposes.

\section{Developing Contingency Probability Groupings}

Probability defines the likelihood of an event in terms of expected outage hours per year. Ranking contingencies by their probability assumes that the expected annual outage duration is a reasonable measure of the impact of outages on the customer. To facilitate in the evaluation, a relative likelihood index was computed for each contingency. The index is the ratio of the probability of the most likely event, a generator outage, to the probability of each event.

As it is not practical to set a separate performance level for each contingency, it was necessary to divide the contingencies into groups. The basic approach was to make the differences between groups greater than the variation within the group. It was considered using both frequency and probability to differentiate between contingency groupings.

The expected outage duration did not vary significantly for the different contingencies with the exception of generator outages that were considerably longer on average. As generator contingencies were also the most frequent, the same groupings were arrived at using either frequency or probability to differentiate between groups.

The results of the contingency ranking are presented in Table I. The contingency events were divided into four groups ( e.g.; high with relative likelihood less than 100, medium with the relative likelihood between 100-4,000, and low with the relative likelihood between 4,000-20,000 and extremely low with the relative likelihood value of greater than 20,000. Since there is some uncertainty in the data, some caution should be observed in assessing the results of the very low probability multiple outages.

TABLE I

RANKED CONTINGENCIES

\begin{tabular}{|c|c|c|c||c|}
\hline \multicolumn{5}{|c|}{ Based on 345 kV Outage Data } \\
\hline Contingency & $\begin{array}{c}\text { Outage Rate, } \\
\text { occ./year }\end{array}$ & $\begin{array}{c}\text { Duration, } \\
\text { hours }\end{array}$ & Probability & $\begin{array}{c}\text { Relative } \\
\text { Likelihood }\end{array}$ \\
\hline Generator & 9 & 81 & 0.08321918 & 1 \\
\hline Two generators & 1.5 & 40.5 & 0.00693493 & 12 \\
\hline Bipolar DC line & 1.41 & 21 & 0.00338014 & 24 \\
\hline Line & 0.8065 & 18 & 0.00165719 & 50 \\
\hline Transformer & 0.0642 & 157 & 0.00115062 & 72 \\
\hline $\begin{array}{c}\text { Bipolar DC Line }+ \\
\text { Generator }\end{array}$ & 0.1478 & 16.68 & 0.00028143 & 296 \\
\hline Line + Generator & 0.0820 & 14.7 & 0.00013760 & 605 \\
\hline $\begin{array}{c}\text { Generator + Transformer } \\
\text { Common tower }\end{array}$ & 0.0157 & 53.4 & 0.00009571 & 870 \\
\hline $\begin{array}{c}\text { Breaker Failure- Insulation } \\
\text { Breakdown }\end{array}$ & 0.001423 & 163 & 0.00002647 & 3,144 \\
\hline $\begin{array}{c}\text { Bipolar DC line +Bipolar } \\
\text { DC line }\end{array}$ & 0.009532 & 10.5 & 0.00001143 & 7,281 \\
\hline Stuck breaker & 0.00635 & 4 & 0.00000290 & 28,696 \\
\hline
\end{tabular}

\begin{tabular}{|c|c|c|c|c|}
\hline Line + Line (independent) & 0.00267 & 9 & 0.00000275 & 30,262 \\
\hline Line + Transformer & 0.0010 & 16.1 & 0.00000184 & 45,228 \\
\hline Two transformers & 0.00014774 & 78.5 & 0.00000132 & 63,045 \\
\hline Bus Section & 0.0023 & 4.7 & 0.00000123 & 67,438 \\
\hline
\end{tabular}

\section{CONTINGENCY BASED SySTEM RELIABILITY PlANNING}

CRITERIA

Very low frequency multiple outages can have a potential for severe impacts. In analyzing these events, the planning process is driven more by their impacts than by their probability. It has been elected not to include these events in system reliability performance table but rather to address them on an individual basis, determining the course of action based on the potential impact.

\section{A. Load Variation}

For a typical power system on a system wide basis, it has been assumed in this paper that loads in excess of 90 percent of the peak occur for less than 4 per cent of the time. Based on an analysis of the actual outage data, it has been found that outage rates during these peak periods were lower than average. Given that some power systems are experiencing low load growth at the present time, building facilities to cover contingencies during peak load levels could result in those facilities only being needed on extremely rare occasions for many years.

It was therefore important to differentiate system reliability performance on the basis of load level and focus primarily on maintaining adequate contingency performance during more likely load levels. The system reliability performance table still specifies a reduced level of performance during peak load periods.

\section{B. $\quad$ System Reliability Performance Table}

Once the formal and consistent framework for the reliability performance table had been established, performance levels could be developed by either:

a)

b) or,

performing a 'generic' value-based analysis using typical system costs, outage data and customer damage costs rationalizing the impact of the planning criteria on specific examples in the system.

A basic tenet of the approach is that customer outage levels should not be dramatically affected by any change in the reliability planning criteria. The performance requirements for high, medium and low probability contingencies are summarized in Table II.

\section{Special application notes for the performance table:}

1) The long-term Delivery Point voltage ranges are specified based on having up to $+/-7 \%$ voltage regulation (could be different for different power systems based on operating policies) available between the transmission and distribution buses at 
the load level indicated. In the event that this is not the case, the criteria should be adjusted accordingly.

2) For non-delivery points, voltages should be controlled to within equipment limitations.

3) Studies should be conducted to assess the impact of very low probability contingencies and where practical, appropriate steps should be taken to ensure that disturbances are contained. The use of Special Protection Scheme (SPS) (including extreme impact SPS) should be considered.

TABLE II

RELIABILITY PERFORMANCE TABLE

\begin{tabular}{|c|c|c|c|}
\hline & $\begin{array}{l}\text { High } \\
\text { Probability } \\
\text { Contingencies }\end{array}$ & $\begin{array}{l}\text { Medium } \\
\text { Probability } \\
\text { Contingencies }\end{array}$ & $\begin{array}{l}\text { Low } \\
\text { Probability } \\
\text { Contingencies }\end{array}$ \\
\hline $\begin{array}{l}\text { Power } \\
\text { Stability } \\
-90 \% \\
\text { duration } \\
\text { loads } \\
\text { - All load } \\
\text { levels }\end{array}$ & System secure & $\begin{array}{l}\text { System secure } \\
\text { Bulk system } \\
\text { secure }\end{array}$ & $\begin{array}{c}\text { Bulk system } \\
\text { secure }\end{array}$ \\
\hline $\begin{array}{l}\text { Voltage } \\
\text { Stability } \\
-90 \% \\
\text { duration } \\
\text { loads } \\
\text { - All load } \\
\text { levels }\end{array}$ & Secure & $\begin{array}{c}\text { Secure } \\
\text { Recoverable }\end{array}$ & Recoverable \\
\hline $\begin{array}{l}\text { Delivery } \\
\text { Point } \\
\text { Voltages } \\
\text { 1) Long-term } \\
\text { Limits } \\
\text { - 90\% } \\
\text { duration } \\
\text { loads } \\
\text { - All load } \\
\text { levels }\end{array}$ & $0.96-1.10$ p.u. & $\begin{array}{c}0.93-1.10 \mathrm{p} . \\
\text { u. }{ }^{*} \\
0.90-1.10 \text { p.u. }\end{array}$ & $\begin{array}{c}0.90-1.10 \text { p.u. } \\
\text { N/A }\end{array}$ \\
\hline $\begin{array}{l}\text { 2) } \\
\text { Contingency } \\
\text { Decrease } \\
\text { - } 90 \% \\
\text { duration } \\
\text { loads } \\
\text { - All load } \\
\text { levels }\end{array}$ & $10 \%$ & $10 \%$ & N/A \\
\hline $\begin{array}{l}\text { 3) } \\
\text { Contingency } \\
\text { Increase }\end{array}$ & $\begin{array}{l}20 \%(2 \mathrm{sec}) \\
10 \% \text { (cont. })\end{array}$ & $\begin{array}{l}20 \%(2 \mathrm{sec}) \\
10 \% \text { (cont.) }\end{array}$ & $\begin{array}{l}20 \%(2 \mathrm{sec}) \\
10 \% \text { (cont. })\end{array}$ \\
\hline $\begin{array}{l}\text { 4) Operating } \\
\text { Changes } \\
\text { - Frequent } \\
\text { Changes } \\
\text { - Infrequent } \\
\text { Changes }\end{array}$ & $\begin{array}{l}4 \% \\
5 \%\end{array}$ & $\begin{array}{l}10 \% \\
10 \%\end{array}$ & $\begin{array}{l}10 \% \\
10 \%\end{array}$ \\
\hline $\begin{array}{l}\text { Thermal } \\
\text { Loading }\end{array}$ & & & \\
\hline
\end{tabular}

\begin{tabular}{|c|c|c|c|}
\hline $\begin{array}{l}-90 \% \\
\text { duration } \\
\text { loads } \\
\text { - All load } \\
\text { levels }\end{array}$ & $\begin{array}{l}\text { Within normal } \\
\text { ratings }\end{array}$ & $\begin{array}{l}\text { Within normal } \\
\text { ratings } \\
\text { Within } \\
\text { emergency } \\
\text { ratings }\end{array}$ & $\begin{array}{l}\text { Within } \\
\text { emergency } \\
\text { ratings }\end{array}$ \\
\hline
\end{tabular}

* Should only be applied in locations where required maintenance outages have been identified.

\section{ApPlication of The Probabilistic CRITERIA IN VALUE-BASED SYSTEM PLANNING}

System improvement projects identified using the performance Table II should be subjected to value-based tests in order to ascertain whether the projects' cost matches or exceeds the customer interruption cost if the projects were not added to the power systems. Reliability of electric service therefore should be based on balancing the costs to a utility and the value of the benefits received by its customers. In order to avoid the risk of over/under building the power systems and provide a rational means of decision making on the necessity of changing service reliability levels experienced by customers, utility costs and the costs incurred by customers associated with interruptions of service must be incorporated in system planning and operating practices [10]-[12]. Value-based planning methods are appealing in that they attempt to mathematically compare the cost of unreliability with the cost of providing additional reliability in order to determine whether the system enhancements are justified.

A value-based reliability planning approach attempts to locate the minimum cost solution where total cost includes the utility investment cost plus the operating cost plus the customer interruption cost. Fig. 2 illustrates how utility costs (i.e., reflected in customer rates) and the customer interruption costs are combined to give the 'total cost'.

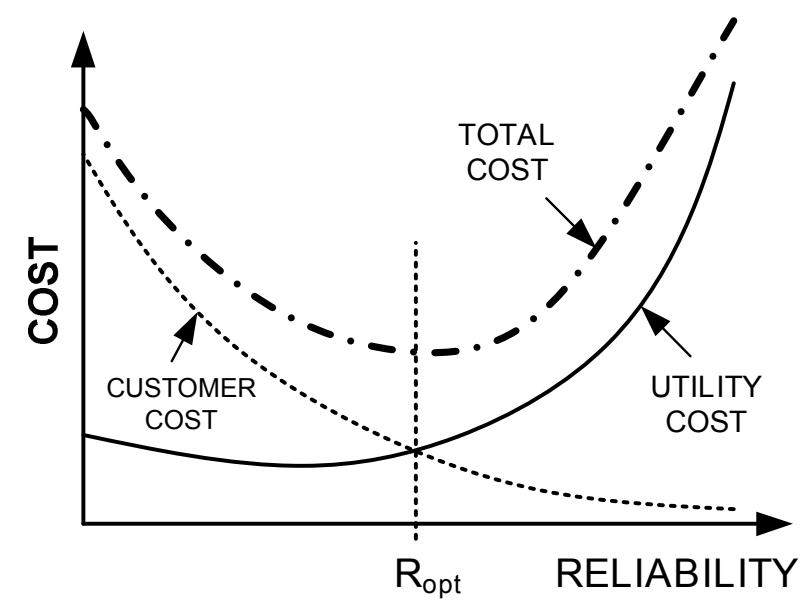

Fig. 2: Concept associated with reliability cost-benefit model

The utility cost curve shows how customer rates go up as more money is spent for increased system reliability levels. The customer interruption cost curve shows how customer cost of interruptions decreases as the system reliability increases. It is also important to note that for low 
levels of system reliability levels, the customer interruption costs are significant. The utility cost curve, however, can also increase significantly in the additional costs of restoring the system to a normal operating state and the loss of revenue (i.e., the utility cost curve shown in Fig. 2 is based on the belief that increased costs will achieve higher levels of system reliability). When the combined utility and customer interruption costs are minimized, then the utility customers will receive the least cost service. Therefore, using the concept of value-based system reliability planning, a given level of service reliability can be examined in terms of the cost and the worth to the customer of providing the electric service from various proposed transmission configurations.

The value-based analysis can add great insight to the transmission system reinforcement problems and has sufficient merit on that basis alone. It would be extremely hard to justify building a project that one could not rationalize provided sufficient benefits to warrant the expected cost. Accordingly, it is important that all potential transmission system improvement projects identified using the reliability performance criteria presented in Section 3 should be subjected to a value-based assessment before their materialization.

As customers will increasingly demand lower rates and higher reliability in the new competitive market, the challenging task of any electric utility will be to minimize the capital investments and operation and maintenance expenditures to hold down electricity rates. If however, the cost is cut too far, it may jeopardize the system's ability to supply reliable power to its customers. This paper presents a customer value-based transmission system expansion and investment technique developed to satisfy ever-increasing customer demands of lower rates and higher service reliability in the competitive market. The developed technique has been applied to a real transmission network reinforcement by evaluating the cost-effectiveness of capital projects identified to be built to alleviate system supply inadequacy. The reliability impacts of the 2004 capital projects on the transmission system were analyzed by using a contingency enumeration based probabilistic reliability model. The expected energy not supplied (EENS) figures for the 2004 system peak loading conditions were computed using with and without 2004 capital projects.

\section{SYSTEM PROBLEM IDENTIFICATION}

A probabilistic reliability assessment of system problems performed for the 2004 summer peak loading conditions for the transmission system of study consisting of $72 \mathrm{kV}, 144 \mathrm{kV}$ and $240 \mathrm{kV}$ systems serving over a million residential, commercial, industrial, and institutional customers revealed that a number of transmission areas lack adequate system facilities for a number of N-1 and N-2 contingencies. Failure criteria considered in the contingency enumeration approach utilized in the reliability index computations are permanent interruptions, overloads, voltage violations and voltage depression. A brief description of the contingency enumeration approach employed in the probabilistic reliability model used in the paper is summarized in the following sections:

\section{A. Contingency Analysis}

The basic contingency enumeration approach to reliability analysis of the transmission system involves the selection and evaluation of the contingencies, the classification of each contingency according to failure criteria and the compilation of appropriate reliability indices. The contingency assessment is capable of detecting system problems such as overloads, bus voltage violations, voltage depression, bus isolation and system separation. The basic steps are illustrated in Fig. 3.

For a specific pre-disturbance condition, a contingency is selected and tested to determine whether the contingency causes any immediate system problem such as a circuit overload or a bus voltage out of limits. If it does not, a new contingency is selected and tested.

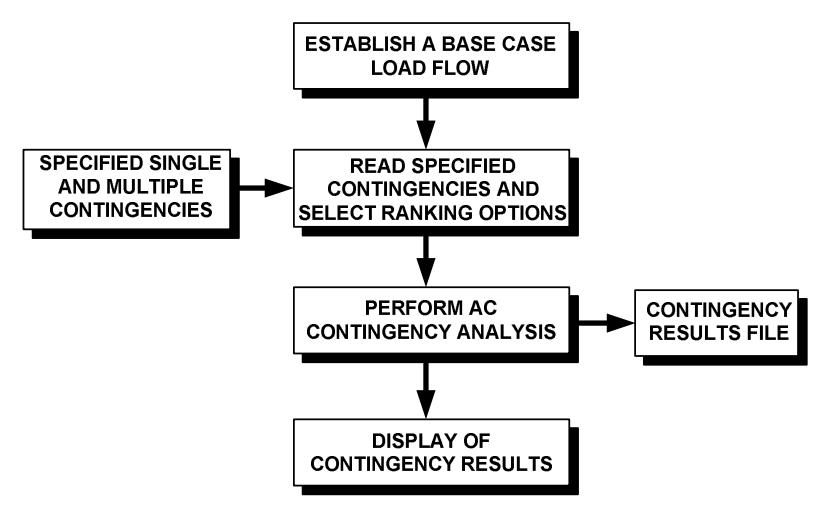

Fig. 3: Basic steps for contingency analysis

The occurrence of a system problem is considered as a failure in the contingency method used in the studies. The possibility of eliminating a system problem by corrective actions was modeled in this approach. The corrective actions employed in the probabilistic reliability model are formulated as an optimal power flow problem with the objective of minimizing load curtailment, MW generation re-dispatched, and transformer phase angle adjusted. It includes a standard AC power flow solution with local automatic adjustments, power system network linearization, and a linear programming solution to relieve the overload and voltage limit violations.

In the reliability studies performed in this paper, independent overlapping outages up to the second level were considered for both generating and transmission elements. Fig. 4 summarizes the results of the reliability assessment performed for the real transmission system identifying the frequency of occurrences of the primary causes of unreliability. 


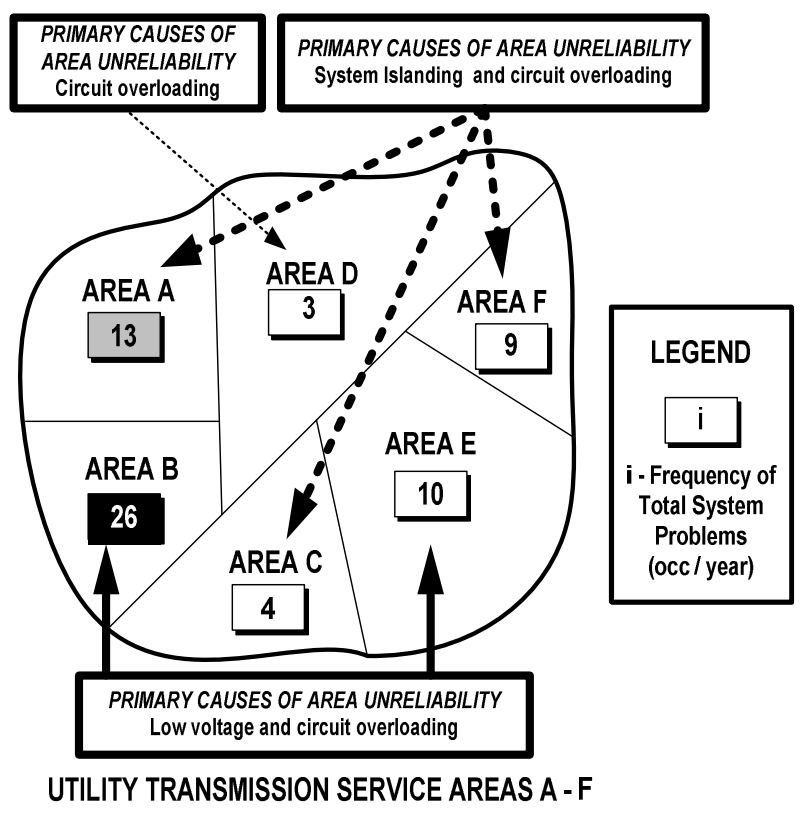

Fig. 4: Frequency of total system problems for different areas of the transmission system

Fig. 4 gives the frequency of total system problems including loss of service continuity, low voltage and voltage depression conditions for different areas of the transmission system. Fig. 5 presents the area overload index.

As shown in Fig. 4 and 5, Area B has the least reliability followed by Area A, Area E and Area F. Low voltage problem and circuit overloading are the primary causes of unreliability for the Area B and Area E, whereas system islanding and circuit overloading are the dominant causes of unreliability in Area A, Area C and Area F. The circuit overloading is the underlying cause of the Area D system unreliability. The reliability assessment performed identified the system weaknesses and permitted identification of appropriate remedial capital projects to alleviate the system reliability issues.

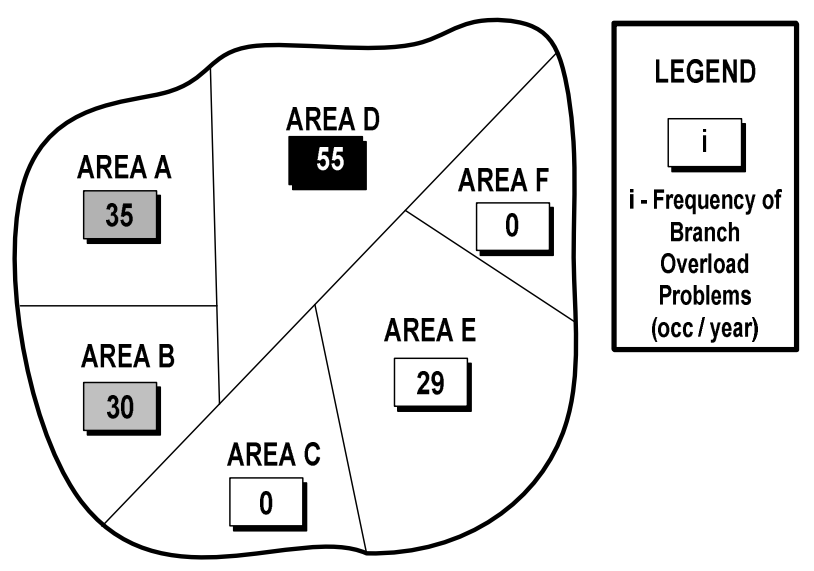

UTILITY TRANSMISSION SERVICE AREAS A - F

Fig. 5: Frequency of branch overload for different areas of the transmission system
In order to mitigate the reliability issues identified, a number of capital projects for different transmission areas were selected. The selected projects were then tested in contingency load flow simulation runs to compare and rank the projects. The capital projects listed in Section IV became the candidate projects in the 2004 capital budget. These projects were further tested whether or not they bring benefits to customers in terms of reduced customer interruption costs.

\section{IDENTIFIED 2004 TRANSMISSION AND DISTRIBUTION SYSTEM CAPITAL PROJECTS}

The following area projects are described in Table III identified by service area are included in the reliability cost-benefit studies in order to ascertain whether or not the capital projects are beneficial from customers' perspective. The distribution projects are primarily related to relieving distribution substation transformer overloads and other distribution needs for each area. The huge single line diagram of the utility system being analyzed is beyond the scope of this paper. There are many substations and transmission lines in this system The significant data is the cost of the project and not the specific details which are beyond the scope of this paper. The key question is: are the costs of transmission line projects to improve the reliability of the system balanced by a reduction in the cost of customer interruptions?

TABLE III

2004 CAPITAL PROJECTS FOR RELIEVING DISTRIBUTION PROBLEMS

\begin{tabular}{|c|c|c|c|c|}
\hline AREA & $\mathbf{A}$ & B & D & $\mathbf{E}$ \\
\hline PROJECT(S) & 1 & 1 & $1-12$ & 1 \\
\hline $\begin{array}{l}\text { Build a new } \\
\text { substation }\end{array}$ & & & yes & \\
\hline $\begin{array}{l}\text { Upgrade an existing } \\
\text { substation }\end{array}$ & yes & & yes & \\
\hline Add a new transformer & yes & yes & yes & \\
\hline Add new switchgear & & yes & & \\
\hline Add new breakers & yes & & yes & \\
\hline $\begin{array}{l}\text { Add new distribution } \\
\text { feeders }\end{array}$ & yes & & & \\
\hline $\begin{array}{l}\text { Build a new transmission } \\
\text { line }\end{array}$ & & & yes & \\
\hline Rebuilt transmission lines & & & yes & \\
\hline Add new capacitor banks & & & & yes \\
\hline $\begin{array}{c}\text { TOTAL AREA } \\
\text { COST }\end{array}$ & $\$ 2,355,000$ & $\$ 1,812,000$ & $\$ 27,514,000$ & $\$ 369,000$ \\
\hline \multicolumn{5}{|c|}{$\begin{array}{c}\text { TOTAL BUDGETED COST } \mathbf{\$ 3 2 , 0 5 0 , 0 0 0} \\
\text { Primarily to relieve distribution substation overloads and } \\
\text { other distribution system needs. }\end{array}$} \\
\hline
\end{tabular}

The total budgeted cost for above 2004 capital projects included in 2004 power flow case is $\$ 32,050,000$. It is important to note that the cost figure of $\mathbf{\$ 3 2 , 0 5 0 , 0 0 0}$ includes the costs for those projects primarily related to relieving distribution substation transformer overloads and other distribution needs.

The transmission related project cost figures are presented in Table IV. 
TABLE IV

2004 TRANSMISSION SYSTEM CAPITAL PROJECTS

\begin{tabular}{|c|l|c|}
\hline $\begin{array}{c}\text { Project } \\
\text { No. }\end{array}$ & \multicolumn{1}{|c|}{ Description } & Cost \\
\hline 1 & $\begin{array}{l}\text { Rebuild the 72 kV line between } \\
\text { substations }\end{array}$ & $\$ 349,000$ \\
\hline 2 & $\begin{array}{l}\text { Install 72 kV line breakers at a } \\
\text { particular substation }\end{array}$ & $\$ 416,000$ \\
\hline 3 & $\begin{array}{l}\text { Rebuild the 72 kV line between } \\
\text { substations }\end{array}$ & $\$ 395,000$ \\
\hline 4 & $\begin{array}{l}\text { Substation A area plan (six } \\
\text { projects) }\end{array}$ & $\$ 8,237,000$ \\
\hline 5 & $\begin{array}{l}\text { Install 25 kV capacitors at a } \\
\text { particular substation }\end{array}$ & $\$ 369,000$ \\
\hline
\end{tabular}

\section{Total Transmission Capital Project Cost $\quad \mathbf{\$ 9 , 7 6 6 , 0 0 0}$}

\section{EQuipMEnT OutAge, Customer OutAge Cost AND LOAD DATA USED IN THE STUDIES}

Outage data for transmission equipment used in the studies were obtained from the company outage database for transmission equipment of $72 \mathrm{kV}$ to $240 \mathrm{kV}$ systems and North American Electric Reliability Council (NERC) Generation Availability Data System (GADS) database for generating units. Generating unit outage data is based on the operating period 1998 to 2002 .

\section{Load data}

In order to calculate the annual expected load lost, the system load duration curve is approximated with a five-step load model with corresponding exposure probability. The five- step load model with corresponding probability is shown in Table V. The five-step load duration curve is derived from the 2004 hourly loading data for the transmission system.

TABLE V

FIVE STEP LOAD DURATION CURVE APPROXIMATIONS

\begin{tabular}{|c|c|}
\hline Load level & Probability \\
\hline $100 \%($ Peak $)$ & 0.001 \\
\hline $80 \%-90 \%$ & 0.025 \\
\hline $70 \%-80 \%$ & 0.040 \\
\hline $60 \%-70 \%$ & 0.097 \\
\hline$<60 \%$ & 0.837 \\
\hline
\end{tabular}

Simulations are run at different load levels such as $100 \%$, $90 \%, 80 \%$, etc. and annual unserved load was calculated by weighting the results of each simulation by the percent of the year that each load level is present.

\section{Customer outage cost data}

The customer damage functions after escalation to 2004 dollars for each sector shown in Fig. 6 are the cost of outage in dollars per kilowatt of peak demand. The sector types considered are industrial users, commercial users, institutional and residential users. Fig. 6 shows the sector customer damage functions for all four sectors, reflecting economic consequences of power cessation as a function of the interruption duration.
The sector customer damage functions can be combined according to the relative representation of the individual sectors in the system of study to create a composite customer damage function (CCDF) [10]-[12]. The system load supplied by the transmission is comprised of 15.99 per cent industrial load, 25.87 per cent commercial load, 9.56 per cent institutional load and 48.58 per cent residential load. The creation of CCDF for the system is an attempt to define the total customer costs for that system as a function of interruption duration. In creating the CCDF, the annual energy consumption for each customer, group, or sector is generally used for weighting costs for longer interruptions and weighting by the annual peak demand is used for durations below $1 \mathrm{~h}$ because of the fact that shorter interruptions result in a power shortage rather than in an energy shortage. As stated earlier, the cost values shown in Fig. 6 represent the economic consequences of power interruption as a function of duration. The power system may experience power interruption of various durations. Longer interruptions may be spread over more customers through load rotation, so that no customer experiences an outage of long duration.

For the purpose of this study, the customer outage cost for contingencies with duration outside the range of the above composite customer damage function is obtained by extrapolating the CCDF.

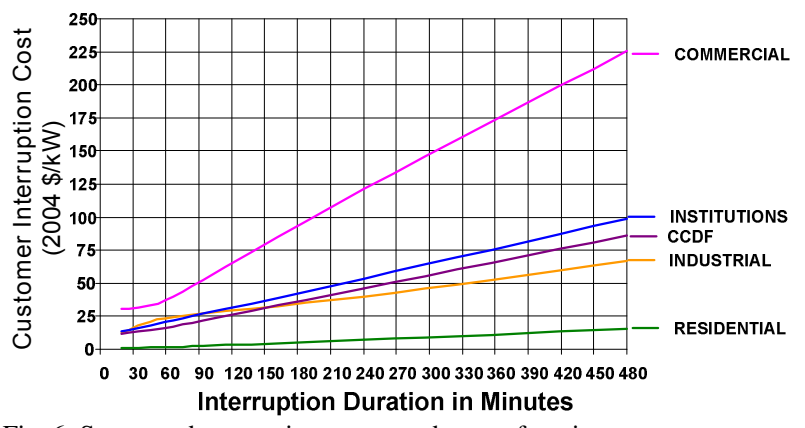

Fig. 6: Sector and composite customer damage functions

The cost impacts of customer load curtailments depend on a number of factors. One of the parameters that influences strongly is the duration of an outage. As shown in Fig. 6, customer interruption cost function is one that relates the cost per $\mathrm{kW}$ of load lost as function of the duration of an outage. An interpolation technique is used to find the specific cost segment based on the duration of each load curtailment. The interruption cost is calculated for a single base case as well as multiple load level cases.

Using the CCDF and the information of interruption durations, the expected cost (ECOST) to customers at a load point $\mathrm{k}$ for all the contingencies can be computed as:

$$
\mathrm{ECOST}_{\mathbf{k}}=\sum_{\mathbf{j}=1} \mathbf{L}_{\mathbf{k j}} * \mathbf{f}_{\mathbf{j}} * \mathbf{c}\left(\mathbf{d}_{\mathbf{j}}\right)
$$

where,

$L_{k}$ - the magnitude of the load curtailed in MW at load point $\mathrm{k}$ for contingency $\mathrm{j}$ 
$f_{j}$ - the frequency (occ / year) of the contingency $\mathrm{j}$

$d_{j}$ - duration (hour) of the contingency $\mathrm{j}$

$c\left(d_{j}\right)$ - the cost of an outage contingency of duration $\mathrm{d}_{\mathrm{j}}$ which can be obtained from the CCDF of the load point $\mathrm{k}$

$\mathrm{NC}$ - the total number of outages that lead to power interruption at load point

The overall expected cost for a number of load points in the transmission system could then be computed as,

$$
\mathrm{ECOST}=\sum_{\mathrm{k}=1}^{\mathrm{NLP}} \mathrm{ECOST}_{\mathrm{k}}
$$

Where,

NLP - the total number of load points in the study system

\section{ReLIABILITy COST-BENEFIT ANALYSIS OF 2004 CAPITAL PROJECTS}

Two compatible power flow base cases were created for analyzing the impact of the 2004 capital projects on the transmission system reliability. The first case included none of the 2004 capital projects listed in Section VI. Generating unit, transmission line and transformer bank outage models were developed reflecting the case without the 2004 capital projects.

The second power flow case included all the 2004 capital projects identified in Section VI. The generating unit, transmission line and transformer bank outage models were modified to reflect the inclusion of the 2004 capital projects. The multi-state load model shown in Table V was used in each power flow case to compute annual EENS figures. The probabilistic reliability model simulated approximately 7,000 contingencies in each case. The failure criteria used are at least one load bus isolated for system separation contingency, the minimum bus voltage is 0.95 p.u., the maximum bus voltage is 1.05 p.u., the line overloading criterion is exceeding line emergency loading, and finally the voltage depression criterion used is 0.8 p.u. at 5 or more buses for a single contingency condition. The contingency depth level considered in the study was one, except in certain known situations, where double or multiple must run contingencies were considered.

\section{ANALYSIS OF RESUlTS}

The value-based reliability analysis is a planning methodology in which the cost of a system facility addition is calibrated against the benefits accrued from the facility addition in terms of supply reliability improvements. It is based on the customer interruption cost data collected through surveys of customer perception regarding the level of reliability they are willing to pay for. In this approach, the incremental reliability improvement due to the facility addition is expressed in terms of dollars and cents, and then compared with the cost of the facility to ascertain the facility's cost-effectiveness.
The computed EENS value for the 2004 power flow case without the 2004 capital projects is 1,641.7 MWh per year. The computed EENS figure when the 2004 capital projects are included in the 2004 power flow case is 699.1 MWh per year. The reduction in the EENS value due the inclusion of the 2004 capital projects is $942.6 \mathrm{MWh}$ per year. The reduction in the total customer interruption cost due to the inclusion of the 2004 transmission capital projects is $\$ 10,142,376$ per year. The total estimated cost of all the 2004 transmission capital projects is $\$ 9,766,000$. A cumulative present value or present worth analysis was performed to ascertain the payback year for the 2004 transmission capital projects. The economic analysis shows that the cumulative present value of the cost of transmission capital projects over the 30 -year project life is $\$ 15,652,262$ in 2004 dollars. The cumulative present value of the unserved energy cost savings due to the inclusion of the 2004 transmission capital projects is $\$ 144,244,872$ in 2004 dollars over the same 30-year project life. The payback year for the cost of the projects is 2 .

It is important to note that the quantification of reliability benefits rendered by capital projects and expressed in terms of dollars and cents, and then comparing the reliability benefits with the project revenue requirements greatly facilitates the identification of the most cost-effective system expansion project to meet the current and future load growth. The value-based reliability methodology in transmission system planning and operating, therefore, essentially eliminates the risk of over/under capacity addition to the system. In other words, the value-based reliability method eliminates the risk of over/under investments in the system that has a direct impact on the customer rates that can influence the customer preferences of choosing an electricity supplier in the competitive market. It is further important to note that the value-based reliability methodology is clearly sensitive to a number of parameters, namely, the customer interruption cost data, the system load data, the customer mix in the service territory, and the transmission and distribution equipment outage duration, failure rate, system load growth trends, and system operating and maintenance constraints. There are a wide variety of applications using this technique to improve supply reliability in the deregulated market environment [13]-[15].

\section{CONClusions}

Reliability and cost are the two major considerations that will decide the winners and losers in the new competitive electricity market. In this era of intense price and service reliability competition, the haphazard and deterministic transmission system reliability improvement planning criteria are no longer valid. It has long been recognized that in order to be able to provide customers with optimum service reliability at the right cost, reliability based planning criteria are inevitable. It is therefore can be concluded that the emerging transmission system organizations responsible for planning, design and overall transmission asset management have to forego the past implicit criteria and start using customer-responsive 
probabilistic value-based criteria in regular planning and design activities.

This paper presents a methodology to derive contingency based probabilistic planning criteria that reflect the stochastic nature of a power system operation. The approach of ranking contingencies based on historical averages is the first step in ascertaining the relative impact of individual equipment outages. By identifying approximate frequencies and probabilities for the different contingency groups, it was possible to determine levels of system performance that will generally lead to projects being proposed which can pass subsequent value based tests. The applicability of non-standard solutions such as controlled load shedding to avoid cascading outages could also be better rationalized in this light.

The concepts and practical applications of a value-based reliability cost-benefit model in evaluating transmission capital projects have been successfully illustrated in this paper using a practical system example. Customer valuebased reliability planning is a valuable approach to transmission system reinforcement and design. The novel methodology presented in this paper is based on customer preferences and is capable of assisting electric utilities to achieve their primary objective of providing reliable electricity at the lowest possible rate.

\section{REFERENCES}

[1] R. Billinton, L. Salvaderi, J. D. McCalley, H. Chao, Th. Seitz, R. N. Allan, J. Odom and C. Fallon, "Reliability issues in today's electric power utility environment", IEEE Transactions on Power Systems, Vol. 12, No. 4, November 1997, pp. 1708 - 1714.

[2] S. V. Vadari and J. D. Hammerly, "New faces and functions in a competitive market", IEEE Computer Applications in Power, Vol. 10, No. 1, January 1997, pp. 47-52.

[3] R, J, Ringlee, P. Albrecht, R. N. Allan, et all, "Bulk power system criteria and indices trends and future needs", IEEE Transactions on Power Systems, Vol. 9. No. 1, February 1994, pp. $181-1990$.

[4] B. L. Silverstein, D. M. Porter, " Contingency Ranking for Bulk System Reliability Criteria", IEEE / PES Transaction on Power Systems, Volume 7, Number 3, August 1992, pp. 956 - 964.

[5] R. Billinton, A. A. Chowdhury, "Generating Unit Models Using the Canadian Electrical Association Data Base", CEA Transaction, Vol. 23, 1984.

[6] R. Billinton and R. N. Allan, "Reliability evaluation of power systems", Plenum Press, New York, 1996.

[7] Mid-Continent Area Power Pool (MAPP)- Composite System Reliability Working Group (CSRWG), "MAPP Bulk Transmission System Outage Report", June 2001.

[8] R. N. Allan, "Concepts of Data for Assessing the Reliability of Composite Systems", IEEE Tutorial on Reliability Assessment of Composite Generation and Transmission Systems, Course Text 90EH0311-1-PWR.

[9] C. R. Heising, et al, "Final Report on High Voltage Circuit Breaker Reliability Data for Use in Substation and System Studies, Report on Behalf of WG 13.06", in Proceedings of CIGRE Conference, Paris, 1994.

[10] R. Billinton, G. Wacker, G. Tollefson, J. Aweya and E. Chan, "Customer requirements for electric service reliability: An NSERC study", CEA Transactions, Vol. 32, 1993.

[11] G. Tollefson, G. Wacker, R. Billinton, E. Chan and J. Aweya, "NSERC customer cost of interruption study - preliminary results", CEA Transactions, Vol. 31, 1992.

[12] A. A. Chowdhury, T. C. Mielnik, L. E. Lawton, M. J. Sullivan and A. Katz, "Reliability worth assessment in electric power delivery systems", in Proceedings of IEEE PES 2004 General Meeting, Denver, Colorado, June 6-10, 2004 (CDROM).
[13] A. A. Chowdhury and D. O. Koval, "Value-based power system reliability planning", IEEE Transactions on Industry Applications, Vol. 35, No. 2, March/April 1999, pp. 305 - 311.

[14] A. A. Chowdhury and D. O. Koval "Value-based distribution system reliability planning", IEEE Transactions on Industry Applications, Vol. 34, No. 1, January/February 1998, pp. $23-29$.

[15] A. A. Chowdhury and D. O. Koval, "Computation of reliability based generation equivalence to a transmission facility in the new competitive electricity market", Proceedings of IEEE / PES summer Power Meeting, Edmonton, Canada, July 18 - 22, 1999, pp. 1024 1030.

\section{BIOGRAPHIES}

Dr. A. A. Chowdhury received his MSc degree with honors in electrical engineering from the Belarus Polytechnic Institute in Minsk, Belarus. His $\mathrm{MSc}$ and $\mathrm{PhD}$ degrees in electrical engineering with specialization in power systems reliability and security were earned at the University of Saskatchewan in Canada, and his MBA degree from the St. Ambrose University in Davenport, USA. He has over 26 years of teaching, research and development, electric utility industry, electric equipment manufacturing industry, and consulting experience in power system reliability and security assessments, planning, and analysis. He is actively involved in the development of probabilistic models, criteria and software for use in power system planning, operating and maintenance. He has given invited lectures on theory and applications of power system reliability and value-based planning nationally and internationally. Dr. Chowdhury has performed original works on power systems reliability and value-based assessments, designed and conducted customer interruption cost surveys, and developed practical system models for use in reliability cost/reliability worth assessments in the emerging competitive electricity market. The numerous reliability methods developed by Dr. Chowdhury are routinely being utilized in electric utility and consulting businesses. He has authored and/or co-authored over 110 technical papers on power system analysis; planning and reliability published in different peer reviewed engineering journals in Asia, Europe and North America. He has received four best prize paper awards from the IEEE (1997), the International Institute for Advanced Studies in Systems Research and Cybernetics (1996 \& 1997) and the 8th International Conference on Probabilistic Methods Applied to Power Systems (PMAPS2004).

Dr. Chowdhury has received the IEEE Region 4 "2003 Outstanding Engineer of the Year Award" for his contributions to the science of power system reliability evaluation. Under his chairmanship and also received the 2005 IEEE Technical Working Group Recognition Award for contribution to the revision and expansion of the IEEE Standard 762-2005: Standard Definitions for Use in Reporting Electric Generating Unit Reliability, Availability, and Productivity. He has received the IEEE Regional Activities Board (RAB) 2005 Achievement Award for his outstanding leadership and contributions and to IEEE and Engineering profession. Dr. Chowdhury has been listed in International Biographical Center's (Cambridge, UK) “2004 Living Legends", Marquis' Who's Who in America, Who's Who in the World, Who's Who in Finance and Business, and Who's Who in Science and Engineering. He is a Fellow of the Institute of Electrical and Electronics Engineers (IEEE), a Fellow of the British Institution of Engineering and Technology (IET), a Chartered Engineer in the United Kingdom, a Fellow of the IEEE, a Registered Professional Engineer in the State of Texas, and in the Province of Alberta, Canada.

Dr. S. M. Islam 